\title{
Diagnostic value of Xpert MTB/RIF assay on pleural tissue obtained via closed pleural biopsy among persons with presumptive tuberculous pleuritis
}

\author{
S D Yoo, ${ }^{1} \mathrm{MD}$; G Abebe, ${ }^{2} \mathrm{PhD}$; J E Yoo, ${ }^{3} \mathrm{MPH}$; D Regassa, ${ }^{4} \mathrm{MPH}$; M Bezabih, ${ }^{5} \mathrm{MD}$ \\ ${ }^{1}$ Department of Internal Medicine, Jimma University Institute of Health, Jimma University, Jimma, Ethiopia \\ ${ }^{2}$ Department of Microbiology, Jimma University Institute of Health, Jimma University, Jimma, Ethiopia \\ ${ }^{3}$ Department of Environmental Health, Jimma University Institute of Health, Jimma University, Jimma, Ethiopia \\ ${ }^{4}$ Department of Epidemiology, Jimma University Institute of Health, Jimma University, Jimma, Ethiopia \\ ${ }^{5}$ Department of Pathology, Jimma University Institute of Health, Jimma University, Jimma, Ethiopia
}

Corresponding author: S D Yoo (yoouga@yahoo.com)

\begin{abstract}
Background. Tuberculous pleuritis (TBP) is a common extrapulmonary tuberculosis that contributes to the tuberculosis burden. Xpert MTB/RIF assay is a promising method for rapid diagnosis of TBP. The diagnostic value of Xpert MTB/RIF assay in pleural tissue obtained via closed pleural biopsy among sputum acid-fast bacilli (AFB) smear-negative persons is not well studied.

Objective. To evaluate the diagnostic value of Xpert MTB/RIF assay on diagnosis of TB in pleural tissue obtained via blind closed pleural biopsy.

Methods. Closed pleural biopsy using Cope needle was performed on adult patients who presented with lymphocyte predominant exudative pleural effusion. Xpert MTB/RIF assay was performed in parallel to pathology and mycobacterial culture of the pleural tissue specimen to determine its sensitivity and specificity. Final clinical diagnosis of TBP was determined by improvement in 2-months follow-up of anti-tuberculous treatment.

Results. A total of 33 patients were included in the study. The median (interquartile range (IQR)) age was 27 (25 - 42) years. The sensitivity and specificity of Xpert MTB/RIF assay was 30\% and 100\% compared with Mycobacterium tuberculosis culture as the gold standard, and $20 \%$ and $95.7 \%$ compared with histopathology as the gold standard.

Conclusion. Xpert MTB/RIF assay in pleural tissue obtained by closed pleural biopsy did not increase diagnostic yield, but it shortens time for diagnosis compared with conventional methods.
\end{abstract}

Afr J Thoracic Crit Care Med 2021;27(1):10-13. https://doi.org/10.7196/AJTCCM.2021.v27i1.120

The burden of tuberculosis remains high, especially in developing countries. Some of these countries are reliant on age-old tuberculosis diagnostic tests such as sputum-smear microscopy, solid culture and chest radiography. Xpert MTB/RIF has recently become widely available in some developing countries. The assay shows high diagnostic accuracy for pulmonary tuberculosis and is highly recommended by the World Health Organization (WHO). ${ }^{[1]}$ However, its diagnostic accuracy for extrapulmonary tuberculosis is highly heterogeneous, yielding results ranging from $25.0 \%$ to $96.7 \%{ }^{[2,3]}$

Tuberculous pleuritis (TBP) is a common form of extrapulmonary tuberculosis. The diagnosis of tuberculous pleural effusion may be definitively established via demonstration of Mycobacterium tuberculosis in the pleural fluid or a pleural biopsy specimen. Measurement of adenosine deaminase (ADA) and interferon-gamma assay in the pleural fluid has also gained wide acceptance in the diagnosis of TB pleural effusions in developed countries. ${ }^{[4]}$ However, these tests are not readily available in most developing countries, including Ethiopia. Xpert MTB/RIF assay in pleural fluid has excellent specificity and lower sensitivity for TBP diagnosis. ${ }^{[5,6]}$ It is not considered as an initial evaluation test among patients with suspected TBP in a high-HIV/TB setting. ${ }^{[7]}$ Pathological diagnosis of TBP was confirmed via closed pleural biopsy, which is time-consuming. Meanwhile, the diagnostic value of the Xpert MTB/RIF assay in tissue biopsies has been reported to be high in some studies and the assay with pleural biopsy is regarded as a reliable tool for the diagnosis of TBP. $^{[8-13]}$ However, the tissue specimens in these studies were obtained by a thoracoscopic biopsy that is not readily available in developing countries. Consequently, the diagnostic value of Xpert MTB/RIF assay in pleural tissue obtained by blind closed pleural biopsy that is readily available in developing countries has not yet been reported.

\section{Methods \\ Participants}

Adult patients who were consecutively admitted to the medical ward at Jimma University Medical Center in Jimma, Ethiopia, between September 2017 and December 2019 were screened for eligibility. Suspicion of TBP was defined by cough of at least 2 weeks with lymphocyte-predominant exudative pleural effusion. Patients with sputum that was smear-positive for acid-fast bacilli (AFB) 
or those who were already receiving antituberculosis treatment at the time of initial evaluation were excluded from the study.

\section{Data collection}

Clinical and demographic information was collected by research officers from study participants using a standardised questionnaire after informed consent was obtained. Chest postero-anterior images were taken if they had not been taken before. Closed pleural biopsy was performed with Cope needle as per standard protocol by two physicians (SY and a resident supervised by SY). Biopsy specimens were divided into three pieces: one piece was sent to the Department of Pathology at Jimma University Medical Center for pathology staining and the other two pieces were sent to the Mycobacteriology Research Laboratory at Jimma University for M. tuberculosis culture using the LowensteinJensen medium and Xpert MTB/RIF assay. Investigators followed the guidelines of Xpert MTB/RIF assay for pleural tissue analysis provided by WHO. ${ }^{[14]}$ Pleural fluid cytology was also performed to rule out the possibility of malignancy whenever the test was available. Vital status was assessed for all patients, either by telephone or in person 2 months after enrollment in the study. The final diagnosis of the participants was comprehensively evaluated based on the result of histology, positive $M$. tuberculosis culture from pleural tissue and clinical judgment after 2-months follow-up with antituberculosis treatment.

\section{Statistical analysis}

Bivariate analysis was performed to compare demographic and clinical characteristics, and outcomes between the patients with confirmed TBP and the non-TB patients, using the $\chi^{2}$ test for dichotomous variables and the Mann-Whitney rank-sum test for continuous variables that are not normally distributed. Statistical analyses were performed using STATA version 14.0 (Stata Corp., USA) with the level of significance specified in reference to a two-tailed, type I error ( $p$-value) of $<0.05$.

\section{Ethics}

The Jimma University Ethical Review Board approved the study protocol before official commencement of the data collection (ref. no. IHPR3002). Informed consent was written in local languages (Amharic or Afaan Oromo)

\section{Results}

A total of 35 adult patients were enrolled in the study but one patient declined to participate and another patient's Xpert MTB/ RIF assay results were lost (Fig. 1).

The median (interquartile range (IQR)) age of the study participants was $27(25-42)$ years and the majority (55\%) were female. There was no significant difference in the clinical findings between those who were diagnosed with TBP and those who had other diagnoses, except that the former were older and had more frequent chest pains than the latter (Table 1).

More than three-quarters of the study participants $(78.8 \% ; n=26 / 33)$ was diagnosed with TBP, $3 \%(n=1 / 33)$ was diagnosed with cancer and $18.2 \%(n=6 / 33)$ had no diagnosis. There were no clinical complications after pleural biopsy in all participants.
Less than a tenth $(7.7 \%$; $n=2 / 26)$ of the patients with confirmed TBP were HIVseropositive. Moreover, a majority of patients $(53.8 \% ; n=14 / 26)$ with confirmed TBP presented with right-sided pleural effusion, $38.5 \%(n=10 / 26)$ presented with left-sided pleural effusion and $7.7 \%$ $(n=2 / 26)$ presented with bilateral pleural effusion (Table 2). There was no underlying parenchymal infiltration, cavitation or lymphadenopathy. The diagnosis of TBP was confirmed in $57.7 \%(n=15 / 26)$ of patients by comprehensive evaluation using histopathology, Xpert MTB/RIF assay and M. tuberculosis culture of pleural tissue. More than one-third $(42.3 \% ; n=11 / 26)$ of patients were clinically diagnosed. Three patients were Xpert MTB/RIF assay-positive and rifampicin sensitive. M. tuberculosis culture was positive in 10 patients including the three patients who were positive on Xpert MTB/RIF assay. Histopathology of 10 patients revealed typical TB with caseous

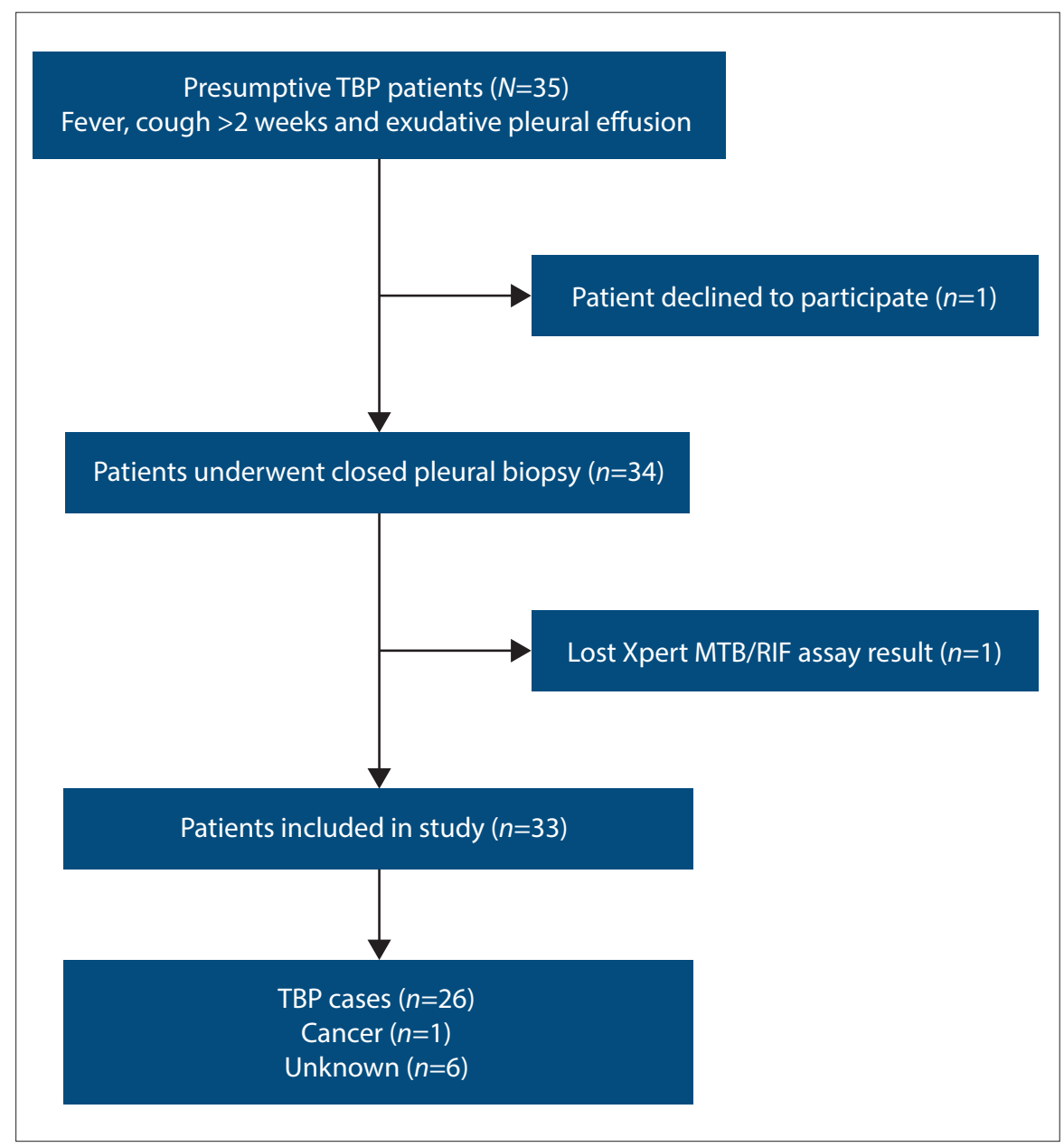

Fig. 1. Number of eligible presumptive tuberculous pleuritis patients enrolled. (TBP = tuberculous pleuritis.) 
necrosis. The percentage (95\% confidence interval (CI)) sensitivity and specificity of Xpert MTB/RIF assay using pleural tissue obtained by closed pleural biopsy were $30 \%$ (18 - 45.2) and $100 \%(83.6$ - 100) when compared with $M$. tuberculosis culture as the gold standard, and 20\% (15.6 - 40.3) and $95.7 \%(78.3$ - 99.2) when compared with histopathology as the gold standard (Table 3).

\section{Discussion}

This is the first report on the diagnostic value of Xpert MTB/RIF assay on pleural tissue obtained by closed pleural biopsy in patients with AFB smear-negative sputum and presumptive TBP. A majority of TBP patients (57.7\%; $n=15 / 26)$ were confirmed by closed pleural biopsy using histopathology, Xpert MTB/RIF assay and M. tuberculosis culture. The majority of study participants (92.3\%) were HIV seronegative. The diagnostic yield of pleural biopsy is known to be higher in HIV-uninfected patients $(50-95 \%)^{[15-17]}$ than in HIV-infected patients $(44-69 \%)$. $^{[18,19]}$ The diagnostic yield of closed pleural biopsy was within the diagnostic range of both groups.

In our study, the sensitivity of the Xpert MTB/RIF assay on closed pleural biopsy tissue was $30 \%$ when compared with $M$. tuberculosis culture as the gold standard. We found the sensitivity to be lower than those

Table 1. Clinical findings of participants $(N=33)$

\begin{tabular}{|c|c|c|c|c|}
\hline Characteristics & $\begin{array}{l}\text { Overall, } \\
n(\%)^{\star}\end{array}$ & $\begin{array}{l}\text { TВP, } \\
n(\%)^{\star}\end{array}$ & $\begin{array}{l}\text { Others, } \\
n(\%)^{\star}\end{array}$ & $p$-value \\
\hline Age, median (IQR) & $27(25-42)$ & $30(23-45)$ & $25(23-40)$ & 0.03 \\
\hline Gender (male) & $15(45.5)$ & $9(34.6)$ & $6(85.7)$ & 0.09 \\
\hline HIV-seropositive & $4(12.1)$ & $2(7.7)$ & $2(28.6)$ & 0.06 \\
\hline Lymphocytes, mean \% in PE & 65 & 76 & 60 & 0.07 \\
\hline Fever & $25(75.8)$ & $23(88.5)$ & $2(28.6)$ & 0.12 \\
\hline Weight loss & $24(72.7)$ & $20(76.9)$ & $4(57.1)$ & 0.63 \\
\hline DIB & $27(81.8)$ & $24(92.3)$ & $3(42.9)$ & 0.05 \\
\hline Chest pain & $21(61.7)$ & $20(76.9)$ & $1(14.3)$ & 0.01 \\
\hline
\end{tabular}

Table 2. Chest X-ray findings of patients with tuberculous pleuritis

\begin{tabular}{|c|c|}
\hline Characteristics & $n(\%)$ \\
\hline \multicolumn{2}{|c|}{ Location of pleural effusion } \\
\hline Right side & $14(53.8)$ \\
\hline Left side & $10(38.5)$ \\
\hline Both side & $2(7.7)$ \\
\hline \multicolumn{2}{|c|}{ Amount of pleural effusion } \\
\hline Small $^{\star}$ & $6(23.08)$ \\
\hline Moderate $^{\dagger}$ & $8(30.77)$ \\
\hline Massive $^{\ddagger}$ & $12(46.15)$ \\
\hline $\begin{array}{l}{ }^{*} \text { Small }=\text { pleural effusion } \\
{ }^{\text {MModerate }}=\text { pleural effus } \\
{ }^{\text {Massive }}=\text { pleural effusio }\end{array}$ & \\
\hline
\end{tabular}

Table 3. Diagnostic value of Xpert MTB/RIF assay compared with different gold standards

\begin{tabular}{llll}
\hline Parameters & $\begin{array}{l}\text { TB culture, } \\
\text { \% (95\% CI) }\end{array}$ & $\begin{array}{l}\text { Histopathology, } \\
\text { \% (95\% CI) }\end{array}$ & $\begin{array}{l}\text { TB culture + } \\
\text { histopathology, \% (95\% CI) }\end{array}$ \\
\hline Sensitivity & $30(18-45.2)$ & $20 \%(15.6-40.3)$ & $20(12.1-33)$ \\
Specificity & $100(83.6-100)$ & $95.7(78.3-99.2)$ & $100(70.1-100)$ \\
PPV & $100(73.1-100)$ & $66.7(46.3-91.2)$ & $100(66.2-100)$ \\
NPV & $23.3(10.6-45.2)$ & $26.7(9.5-46.9)$ & $40(21.2-65.3)$ \\
TB = tuberculous pleuritis; CI = confidence interval; PPV = positive predictive value; NPV = negative predictive value.
\end{tabular}

reported in other studies. The reported sensitivity of PCR is highly heterogeneous, ranging between $45 \%$ and $100 \%$, depending on the method of PCR assay, gold standards and method of biopsy. ${ }^{[9-11,20-22]}$ The conventional PCR studies ${ }^{[20-22]}$ reported higher sensitivity (56 - 100\%) than the Xpert MTB/RIF assay studies (30 - 85\%). ${ }^{[9-11]}$ Most studies obtained pleural tissue by either computed tomography-guided biopsy ${ }^{[22]}$ or thoracoscopic biopsy. ${ }^{[10,11,20]}$ Only one study obtained pleural tissue via closed pleural biopsy. ${ }^{[21]}$ The closed pleural biopsy study used conventional PCR and its sensitivity was $90 \%,{ }^{[21]}$ which is much higher than our results. Further studies may be required to determine whether the differences in methods used to obtain the specimen affect the diagnostic yield of PCR assays. In our study, the sensitivity of Xpert MTB/RIF assay was higher when $M$. tuberculosis culture was the gold standard than when tissue pathology was the gold standard ( $30 \%$ v. $20 \%$; $p=0.05$ ). This finding is consistent with other studies that used tissue pathology as the gold standard and reported a sensitivity of $45-52.2 \% .{ }^{[10,11]}$ The studies that used M. tuberculosis culture as the gold standard reported sensitivity in the range of $85-100 \%{ }^{[9,20,21]}$ It is unclear why the sensitivity of the PCR assay is higher when using $M$. tuberculosis culture as the gold standard than when using tissue pathology as the gold standard. One possibility may be that the former might have used the same biopsy samples for both tissue culture and PCR assays while the latter may have used a different biopsy tissue for PCR assay and pathology, as we did in our study. The sensitivity of our study is slightly lower than the two studies that used Xpert MTB/RIF in thoracoscopic pleural biopsy specimens that showed sensitivity of $45 \%$ and $52 \% .{ }^{[10,11]}$ It is known that the diagnostic sensitivity in pleural tissue obtained via closed percutaneous needle biopsy is lower than that obtained via thoracoscopy in TBP diagnosis. ${ }^{[23,24]}$

A tenth of patients $(11.5 \% ; n=3 / 26)$ with confirmed TBP were positive on Xpert MTB/ RIF assay in our study, which is a much lower detection rate compared with $M$. tuberculosis culture (38.5\%) or histopathology (38.5\%). Moreover, three patients with positive Xpert MTB/RIF results were also $M$. tuberculosis culture positive. This indicates that Xpert 
MTB/RIF assay did not contribute to diagnostic yield in our study. Nevertheless, Xpert MTB/RIF assay of pleural tissue is still useful because it provides rapid results and $M$. tuberculosis culture is not available in many parts of developing countries. Closed pleural biopsy should not be discouraged in such countries for several reasons: (i) pleural tissue produces better diagnostic outcome than pleural fluid in TB diagnosis; ${ }^{[10,20]}$ (ii) tissue pathology may provide an opportunity to diagnose diseases other than TB; and (iii) it has minimal complications in experienced hands although it is an invasive method. ${ }^{[25]}$

\section{Study limitation}

The limitation of this study was that the statistical power was low because of the small sample size.

\section{Conclusion}

Xpert MTB/RIF assay in pleural tissue obtained by closed pleural biopsy has low sensitivity and high specificity. It has a diagnostic value in developing countries where precise pleural fluid analysis is unavailable and considering its availability as well as rapid time to results.

\section{Declaration. None.}

Acknowledgements. None.

Author contributions. SY initiated and conceptualised the study. GA did Xpert/MTB analysis and contributed to the intellectual content. JY analysed the data and wrote the first draft of the manuscript. DR performed statistical analysis, drafted tables and a figure. MB did pathological analysis and contributed to the final version. All authors edited and approved the manuscript for publication.

Funding. This work was supported by the Korea International Cooperation Agency (KOICA) to build and strengthen tuberculosis diagnosis capacity at Jimma University.

Conflicts of interest. None.

1. World Health Organization. Automated real-time nucleic acid amplification technology for rapid and simultaneous detection of tuberculosis and rifampicin resistance: Xpert MTB/RIF assay for the diagnosis of pulmonary and extrapulmonary TB in adults and children: Policy update. Geneva: WHO, 2013.

2. Friedrich SO, von Groote-Bidlingmaier F, Diacon AH. Xpert MTB/RIF assay for diagnosis of pleural tuberculosis. J Clin Microbio 2011;49(12):4341-4342. https://doi. org/10.1128\%2FJCM.05454-11

3. Ligthelm LJ, Nicol MP, Hoek KG, et al. Xpert MTB/RIF for rapid diagnosis of tuberculous lymphadenitis from fine-needle-aspiration biopsy specimens. J Clin Microbio 2011;49(11):3967-3970. https://doi.org/10.1128/jcm.01310-11

4. Mollo B, Jouveshomme S, Philippart F, Pilmis B. Biological markers in the diagnosis of tuberculous pleural effusion. Ann Biol Clin 2017;75(1):19-27. https://doi.org/10.1684/ abc. 2016.1201
5. Sehgal IS, Dhooria S, Aggarwal AN, Behera D, Agarwal R. Diagnostic performance of Xpert MTB/RIF in tuberculous pleural effusion: Systematic review and meta-analysis. J Clin Microbio 2016;54(4):1133-1136. https://doi.org/10.1128\%2FJCM.03205-15

6. Denkinger CM, Schumacher SG, Boehme CC, et al. Xpert MTB/RIF assay for the diagnosis of extrapulmonary tuberculosis: A systematic review and meta-analysis. Eur Respir J 2014;44(2):435-446. https://doi.org/10.1183/09031936.00007814

7. Lusiba JK, Nakiyingi L, Kirenga BJ, et al. Evaluation of Cepheid's Xpert MTB/Rif test on pleural fluid in the diagnosis of pleural tuberculosis in a high prevalence HIV/TB setting. PLoS ONE 2014;9(7):e102702. https://doi.org/10.1371/journal.pone.0102702

8. Raviglione MC. Tuberculosis. In: Jameson JL, ed. Harrison's Principles of Internal Medicine. New York: McGraw Hill Education, 2018.

9. Du J, Huang Z, Luo Q, et al. Rapid diagnosis of pleural tuberculosis by Xpert MTB/RIF assay using pleural biopsy and pleural fluid specimens. J Res Med Sci 2015;20(1):26-31.

10. Christopher DJ, Dinakaran S, Gupta R, et al. Thoracoscopic pleural biopsy improves yield of Xpert MTB/RIF for diagnosis of pleural tuberculosis. Respir 2018;23(7):714717. https://doi.org/10.1111/resp.13275

11. Akhter N, Sumalani KK, Chawla D, Ahmed Rizvi N. Comparison between the diagnostic accuracy of Xpert MTB/Rif assay and culture for pleural tuberculosis using tissue biopsy. ERJ Open Res 2019;5(3).00065-2019 https://doi. org/10.1183/23120541.00065-2019

12. Ozkutuk N, Surucüoglu S. Evaluation of the Xpert MTB/RIF assay for the diagnosis of pulmonary and extrapulmonary tuberculosis in an intermediate-prevalence setting. Mikrobiyoloji Bul 2014;48(2):223-232. https://doi.org/10.5578/mb.7456

13. Suzana S, Ninan MM, Gowri M, et al. Xpert MTB/Rif for the diagnosis of extrapulmonary tuberculosis - an experience from a tertiary care centre in South India. Trop Med Int Health 2016;21(3):385-392. https://doi.org/10.1111/tmi.12655

14. World Health Organization. Xpert MTB/RIF implementation manual. Annex 2 standard operating procedure (SOP) for processing extrapulmonary specimens (CSF, lymph nodes and other tissues) for Xpert MTB/RIF assay. Geneva: WHO, 2017

15. Gopi A, Madhavan SM, Sharma SK, Sahn SA. Diagnosis and treatment of tuberculous pleural effusion in 2006. Chest 2007;131(3):880-889. https://doi.org/10.1378/ chest.06-2063

16. Kirsch CM, Jensen WA, Kagawa FT, et al. The optimal number of pleural biopsy specimens for a diagnosis of tuberculous pleurisy. Chest 1997;112(3):702-706. https:// doi.org/10.1378/chest.112.3.702

17. Sah S. State of the art: The pleura. Am Rev Respir Dis 1988;138:183-234. https:// doi:10.1164/ajrccm/138.1.184

18. Relkin F, Aranda CP, Garay SM, et al. Pleural tuberculosis and HIV infection. Ches 1994;105(5):1338-1341. https://doi.org/10.1378/chest.105.5.1338

19. Frye MD PC, Sahn SA. Tuberculous pleuritis and HIV disease. Chest 1995;108:102S

20. Amer S, Hefnawy AE, Wahab NA, Okasha H, Baz A. Evaluation of different laboratory methods for rapid diagnosis of tuberculous pleurisy. Int J Mycobacteriol 2016;5(4):437-445. https://doi.org/10.1016/j.ijmyco.2016.07.001

21. Hasaneen NA, Zaki ME, Shalaby HM, El-Morsi AS. Polymerase chain reaction of pleural biopsy is a rapid and sensitive method for the diagnosis of tuberculous pleural effusion. Chest 2003;124(6):2105-2111. https://doi.org/10.1378/chest.124.6.2105

22. Li L, Wang Y, Zhang R, et al. Diagnostic value of polymerase chain reaction/acidfast bacilli in conjunction with computed tomography-guided pleural biopsy in tuberculous pleurisy: A diagnostic accuracy study. Med 2019;98(29):e15992. https:// doi.org/10.1097/md.0000000000015992

23. Diacon AH, Van de Wal BW, Wyser C, et al. Diagnostic tools in tuberculous pleurisy: A direct comparative study. Eur Respir J 2003;22(4):589-591. https://doi.org/10.118 3/09031936.03.00017103a

24. Emad A, Rezaian GR. Diagnostic value of closed percutaneous pleural biopsy v. pleuroscopy in suspected malignant pleural effusion or tuberculous pleurisy in a region with a high incidence of tuberculosis: A comparative, age-dependent study. Respir Med 1998;92(3):488-492. https://doi.org/10.1016/s0954-6111(98)90296-7

25. Poe RH, Israel RH, Utell MJ, et al. Sensitivity, specificity, and predictive values of closed pleural biopsy. Arch Intern Med 1984;144(2):325-328.

Accepted 21 January 2021. 